\title{
Differential expression of sonic hedgehog in lung adenocarcinoma and lung squamous cell carcinoma
}

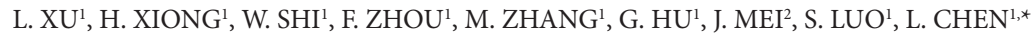 \\ ${ }^{1}$ Center for Experimental Medicine, The First Affiliated Hospital of Nanchang University, Nanchang, Jiangxi 330006, China; ${ }^{2}$ Department of \\ Pathology, The First Affiliated Hospital of Nanchang University, Nanchang, Jiangxi 330006, China \\ ${ }^{*}$ Correspondence: liminchen@ncu.edu.cn
}

Received December 28, 2018 / Accepted March 20, 2019

\begin{abstract}
Overexpression of Sonic hedgehog (Shh) is associated with progression of several cancers. The expression of Shh in non-small cell lung cancer (NSCLC) has been reported with inconsistent results. Lung adenocarcinoma (LAC) and lung squamous cell carcinoma (LSCC) are two major subtypes of NSCLC, which have different genetic genotypes and clinical therapeutic options. The expression of Shh in specimen of patients with NSCLC has yet to be comprehensively determined according to histological subtypes. Shh expression level was determined in 167 NSCLC patients (56 LAC patients and 111 LSCC patients) by immunohistochemical assay (IHC) and disease-free survival and overall survival of patients were analyzed using the Kaplan-Meier method. Shh protein level in pleural effusion from patients with pneumonia or pleural empyema, tuberculosis, LAC and LSCC was measured with enzyme-linked immunoassay (ELISA). We found that Shh expression is increased in tumor tissues from both LAC and LSCC patients compared with the paired adjacent tissues, while Shh level is negatively correlated with tumor differentiation only in LSCC, LSCC patients containing higher-Shh expression have a poorer prognosis. Furthermore, Shh level is elevated in pleural effusion from LSCC patients compared with that of parapneumonic and LAC pleural effusion. Shh expression in tumor tissues or pleural effusion may represent a potential diagnostic and prognostic marker of LSCC patients, pleural effusion Shh may assist to distinguish between LAC and LSCC.
\end{abstract}

Key words: sonic hedgehog, non-small cell lung cancer, lung adenocarcinoma, lung squamous cell carcinoma, tumor tissue, pleural effusion

Lung cancer, the leading cause of cancer-related mortality worldwide, is traditionally classified into small cell lung cancer (SCLC) and non-small cell lung cancer (NSCLC). NSCLC accounts for about $85 \%$ of newly diagnosed lung cancers. NSCLC is further classified into two principal subtypes, lung adenocarcinoma (LAC) and lung squamous cell carcinoma (LSCC) [1]. LAC arises in the distal airway. LSCC arises in the proximal airway, which is strongly associated with smoking. LAC and LSCC have different histopathologic characteristics, genetic genotypes and clinical therapeutic options [2]. Generally, hematoxylin and eosin (HE) staining is used to distinguish tissue types of LSCC and LAC. Immunohistochemical (IHC) staining assists to evaluate p63, p40 and CK5/6 (cytokeratin 5/6) for LSCC, and TTF1 (thyroid transcription factor 1), NapsinA and CK7 for LAC, to distinguishing the two tissue types [3].

Three Hedgehog (Hh) homologues have been identified in mammals, including Sonic hedgehog (Shh), Indian hedgehog (Ihh), and Desert hedgehog (Dhh), which are involved in embryogenesis, organogenesis and tumorigenesis [4]. Shh is the most widely characterized Hh homolog and has been shown to be essential for proper embryonic development [5]. Shh gene encodes a $45 \mathrm{kDa}$ precursor protein, which is autocatalytically cleaved to a $20 \mathrm{kDa} N$-terminal fragment (N-Shh) and a $25 \mathrm{kDa}$ C-terminal fragment [6]. The N-Shh is the well-known active Shh component that is secreted into extracellular space and responsible for all known Shh biological activity. Extracellular Shh binding to its membrane receptor PTCH1 results in the activation of $\mathrm{Hh}$ signaling [7]. Shh-PTCH1 complex actives the seven transmembrane protein smoothened (Smo), which in turn actives the transcription factor Glis and results in transcriptional activation of target genes $[4,8]$. Hh signaling target genes, including Bcl2, Sox 2 and Cyclin D1, all play important roles in cell proliferation, apoptosis and self-renewal $[9,10]$.

The tightly regulated $\mathrm{Hh}$ signaling is crucial for vertebrate development [11]. Recently, there have been numerous studies showing that aberrant activity of Hedgehog (Hh) 
signaling is implicated in a large number of cancers, such as basal cell carcinoma, medulloblastoma, gastric cancer and lung cancer [12-16]. They reported that overexpression of Shh has been associated with cancer, including SCLC and NSCLC [15, 17-19]. Hh signaling involvement in the development of SCLC has been well studied, the progression of SCLC requires Shh, as demonstrated by a mouse model of SCLC [15]. Expression of Hh signaling components including Shh, determined by tissue microarray with 81 samples form 42 NSCLC patients, have no correlation with clinical outcome [20], while high expression of Shh in tumor tissues from patients with NSCLC was reported [18]. However, the expression of Shh in specimen of patients with NSCLC still needs to be determined according to sub-type of tumor.

At the time of initial diagnosis, $\sim 15 \%$ of lung cancer patients have pleural effusion. In the course of progression of lung cancer, about $50 \%$ of patients develop pleural effusion [21]. Active Shh is a secreted protein, but the detection of its presence in pleural effusion and any differences in levels of Shh between LAC and LSCC remains to be uncovered. Traditionally, patients with malignant pleural effusion have a poor prognosis. Shh protein levels in benign pleural effusion and malignant pleural effusion also need to be evaluated.

In this study, we collected specimens of patients with LAC or LSCC and determined Shh expression with an IHC assay. The data showed that Shh is highly expressed in both LAC and LSCC tumor tissues, but negative correlation of Shh expression with tumor differentiation only occurred in LSCC. High Shh expression correlated with poor survival in LSCC patients. Furthermore, pleural effusion from patients with parapneumonic, tuberculous, LAC or LSCC was collected and enzyme-linked immunoassay (ELISA) was carried out to detect Shh protein level, and the results demonstrated that Shh level in LSCC pleural effusion is higher than that in parapneumonic and LAC pleural effusion. Therefore, Shh may be used as a diagnostic and prognostic marker for LSCC and assist to distinguish LAC and LSCC.

\section{Patients and methods}

Human tissue specimens. Human tissue and the paired adjacent specimens were obtained by surgical intervention without prior radiotherapy or chemotherapy. All samples, with complete clinical data, were collected at The First Affiliated Hospital of Nanchang University from June 2011 to March 2014. The diagnosis of LSCC and LAC is according to histopathologic characteristic according to HE staining. Pathologic diagnoses according to the established criteria of the WHO and the $7^{\text {th }}$ edition TNM staging according to the criteria of UICC were determined. Detailed clinical and pathological patients' information are summarized (Table 1 and 2). The study protocol was approved by the Institutional Review Board of The First Affiliated Hospital of Nanchang University.
Western blot. Lysates of tissue specimens were prepared with RIPA buffer containing protease inhibitor cocktail and protein concentrations were determined using BCA protein assay kit (Thermo Scientific). Cell lysate proteins $(100 \mu \mathrm{g})$ were separated on SDS-PAGE and transferred to nitrocellulose membranes, which were immunoblotted with specific primary antibodies and incubated with horseradish peroxidase-conjugated secondary antibodies. The primary antibody Shh was obtained from Santa Cruz and GAPDH was purchased from Cell Signaling Technology.

Immunohistochemistry (IHC) staining was performed as described previously [14]. Each specimen was scored for the intensity of cytoplasmic staining (no staining $=0$, weak staining $=1$, moderate staining $=2$, strong staining $=3$ ) and for the extent of stained cells $(0 \%=0,1 \sim 24 \%=1,25 \sim 49 \%$ $=2,50 \sim 74 \%=3,75 \sim 100 \%=4)$. The immunoreactive score results from multiplying the intensity score by the extent score. To distinguish cancer tissues from adjacent normal epithelium, consecutive sections were stained by hematoxylin and eosin (H\&E).

Diagnostic criteria for pleural effusion. Parapneumonic pleural effusion was defined by any pleural effusion from patients with pneumonia or pleural empyema. Tuberculous pleural effusion was collected from patients with tuberculosis. LAC and LSCC pleural effusions were diagnosed according to the presence of malignant cells in pleural effusion or in biopsy specimens.

Collection of pleural effusion specimens. Pleural effusion specimens were collected by thoracentesis and centrifuged at $2000 \times \mathrm{g}$ for $10 \mathrm{~min}$. Pleural fluid supernatants were stored at $-70{ }^{\circ} \mathrm{C}$ until tested.

Enzyme-linked immunoassay (ELISA). Pleural effusion was diluted 5 times and Shh protein level was measured using a commercially available ELISA kit (Human sonic hedgehog ELISA kit; Westang Inc., China), according to the manufacturer's instructions. This is a sandwich immunoassay using HRP-labeled antibody for the detection of Shh. A standard curve was created using measurements at the following Shh concentrations: 150, 300, 600, 1200 and $1800 \mathrm{ng} / \mathrm{l}$. The assay range of this method was 100-2000 ng/l.

Statistical analysis. The difference of Shh expression in tumor tissue and adjacent tissue of LAC or LSCC was assessed by Student's t-test (LAC: two sided $\alpha=0.05$, power $=0.99$; LSCC: two sided $\alpha=0.05$, power $=1.00)$. The difference between four groups of pleural effusion was assessed by One-way ANOVA. Differences were considered significant if $p<0.05$. Power analysis was performed using $G^{\star}$ Power 3.1 software and all statistical analyses were carried out with SPSS v.13.0 software (SPSS Inc.).

\section{Results}

Shh is increased in tumor tissues of LAC. Firstly, 8 pairs adjacent and carcinoma tissues from patients with NSCLC, randomly enrolled, were subjected to western blot assay and 
the data showed that Shh was increased in NSCLC tumor tissues (Figure 1A). To detect Shh level in specimens of patients with LAC, tissues from 56 LAC cases were used to determine Shh expression with IHC assay. We found that Shh expression that was detected in cytoplasm was higher in LAC tumor tissues than that in these paired adjacent tissues (Figure 1B). Then, the intensity of cytoplasmic staining (no staining $=0$; weak staining $=1$, moderate staining $=2$, strong staining $=3)$ and the extent of stained cells $(0 \%=0,1 \sim 24 \%=$ $1,25 \sim 49 \%=2,50 \sim 74 \%=3,75 \sim 100 \%=4$ ) of each specimen was scored. The immunoreactive score, a score of 0 to 12 , was a product of intensity score multiplied by extent score, which was used to estimate the expression of Shh. According to the statistical data, Shh score in LAC tumor tissue was higher than that of adjacent tissues (Figures 1C-1D). According to the above Shh score, we further defined the score of less than 6 as a low expression, and of equal or more than 6 as a high expression. However, the expression of Shh in LAC samples had no correlation with gender, age, smoke, degree of differentiation, tumor size, lymphatic invasion, or TNM

A

Patient 1 Patient 2 Patient 3 Patient 4 Patient 5 Patient 6 Patient 7 Patient 8
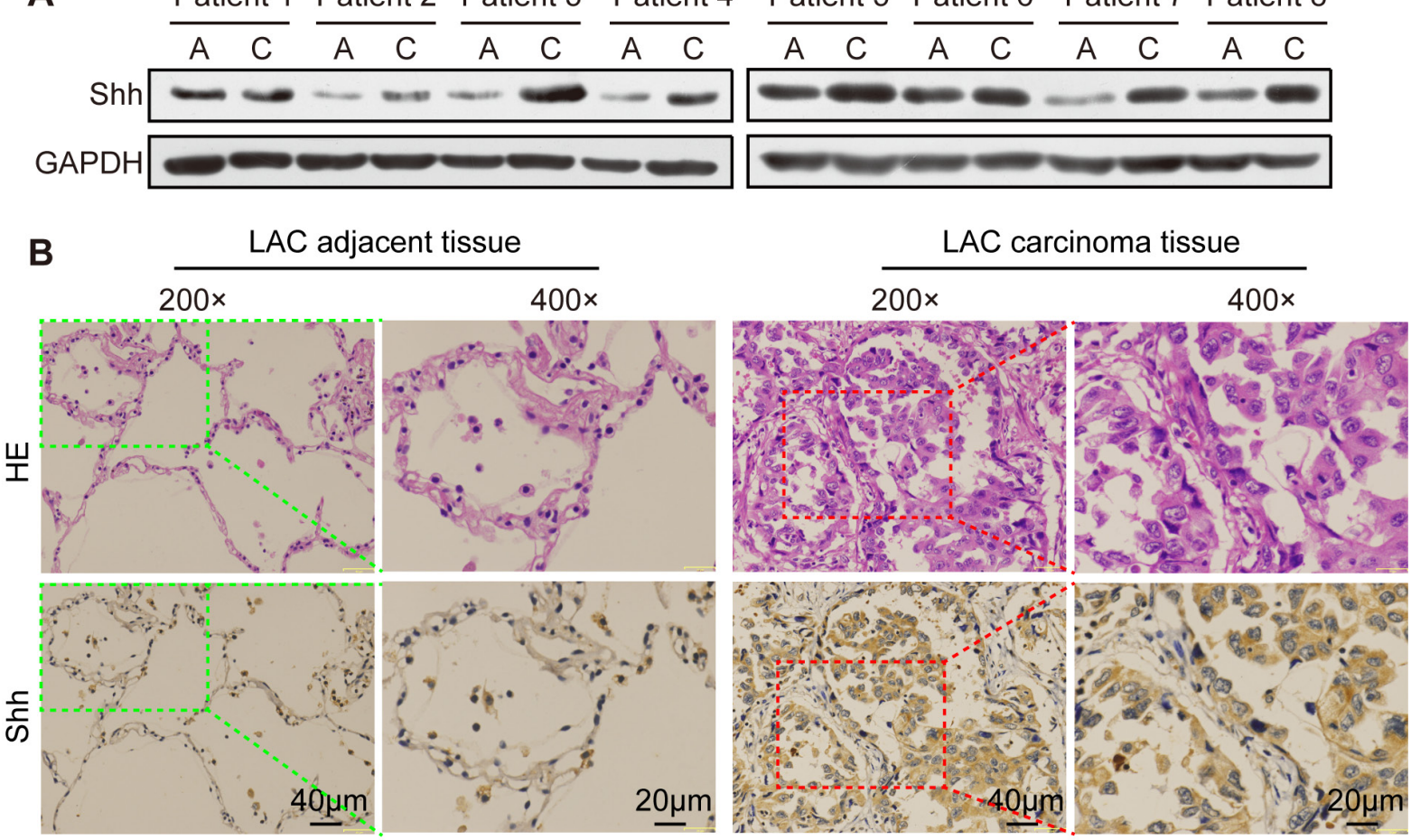

\section{C}
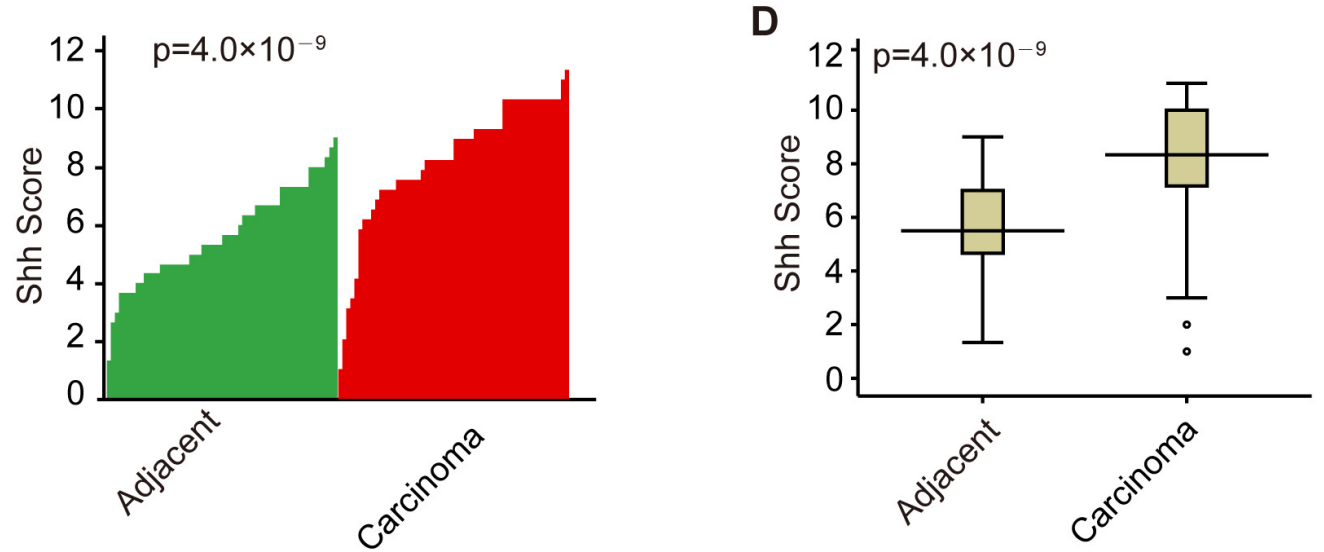

Figure 1. Shh high expresses in LAC tumor tissues. A) Shh is highly expressed in tumor tissues of NSCLC determined by western blot assay. A - adjacent non-tumorous tissue; C - cancer tissue. B) Shh is overexpressed in LAC tissues compared with adjacent tissues as examined by IHC. The representative images are shown. C) Shh scores in each LAC carcinoma and adjacent tissues were plotted. D) Box plot of Shh expression scores is shown. Statistical significance was analyzed using the Mann-Whitney $U$ test, $n=56$. 
stage (Table 1). These results demonstrated that Shh expression was increased in LAC tumor tissues.

Shh highly expressed in tumor tissues of LSCC. LSCC comprises about $30 \%$ of NSCLC. To determine the level of Shh in LSCC, we evaluated 111 recruited eligible LSCC cases and analyzed the expression of Shh by IHC assay. The data demonstrated that the protein level of Shh was significantly increased in LSCC tissues compared to the paired adjacent tissues as detected by IHC analysis (Figure 2A). Shh expression was scored and analyzed as described above. Shh score of LSCC tumor tissue was significantly higher than that of adjacent tissues (Figures 2B-2C). Therefore, these results indicated that Shh is highly expressed in LSCC tumor tissues.

Shh expression negatively correlates with prognosis in LSCC. Next, we analyzed the correlation of Shh expression with the prognosis of LSCC. Shh level was classified as a low expression and a high expression as above, pathologic diagnoses according to the established criteria of the WHO and the $7^{\text {th }}$ edition TNM staging according to the criteria of UICC were determined. We found that the expression of Shh in LSCC samples was strongly correlated with both the degree of differentiation $(\mathrm{p}=0.045)$ and tumor size $(\mathrm{p}=0.015)$ (Table 2). The IHC assay also showed that poorly differentiated tumor tissue had higher expression of Shh than that in moderately or well-differentiated tumor tissue (Figure 3A). Using Kaplan-Meier method, univariate analysis of tumor samples for disease-free survival and overall survival revealed that the group of patients with lower Shh expression displayed a better prognosis compared with the group of patients with higher Shh expression (Figures 3B-3C). Taken together, Shh expression is negatively correlated with differentiation of LSCC tumor and prognosis of LSCC.

Shh protein level is elevated in pleural effusion from LSCC. Considering that active Shh is a secreted protein, we tested whether Shh was present in pleural effusion, and whether Shh protein level was increased in pleural effusion
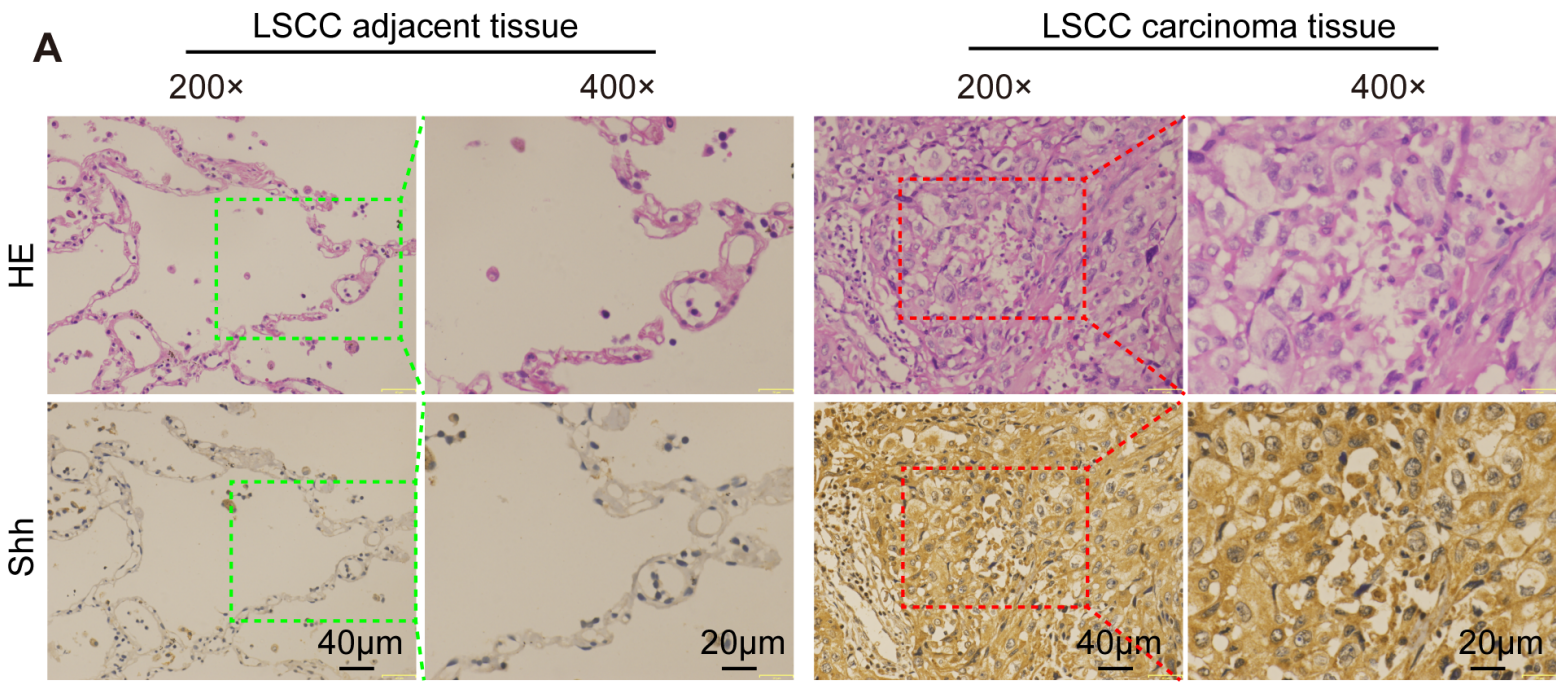

B

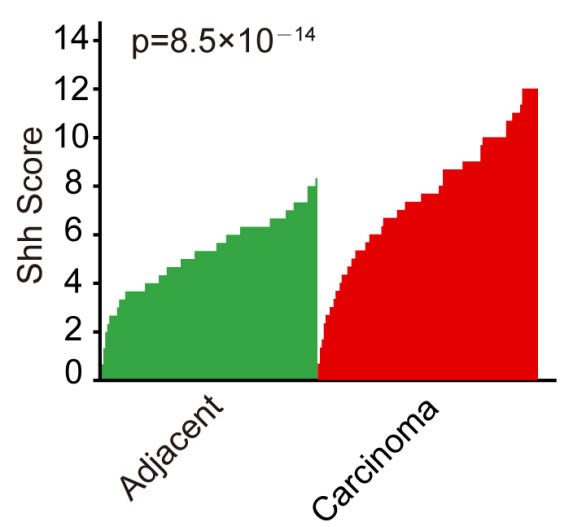

C

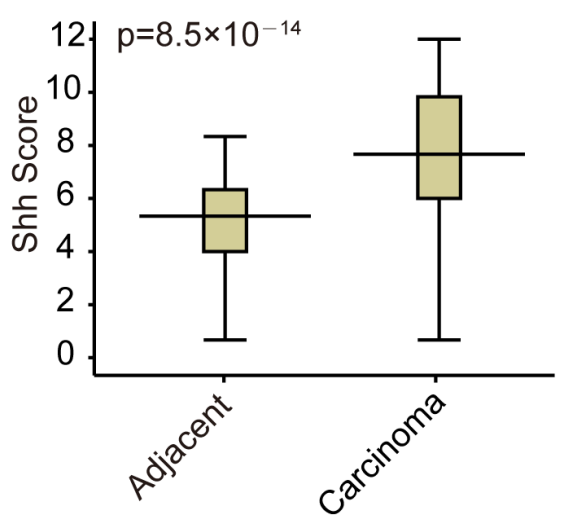

Figure 2. Shh overexpresses in tumor tissues of LSCC. A) Shh is overexpressed in LSCC tissues compared with adjacent tissues as evaluated by IHC, representative images are shown. B-C) Plotting the Shh scores in carcinoma and adjacent tissue of each LSCC (B) and box plots of the scores of Shh expression (C) are presented. Statistical significance was analyzed using the Mann-Whitney $U$ test, $n=111$. 
Table 1. Association of Shh expression levels with clinicopathologic characteristics in LAC.

\begin{tabular}{|c|c|c|c|c|c|}
\hline \multirow{2}{*}{$\begin{array}{l}\text { Clinicopathologic } \\
\text { Characteristics }\end{array}$} & \multirow{2}{*}{$\mathbf{n}$} & \multicolumn{2}{|c|}{ Shh expression } & \multirow{2}{*}{$\chi^{2}$ value } & \multirow{2}{*}{ p-value } \\
\hline & & low (\%) & high (\%) & & \\
\hline Gender & 56 & & & & \\
\hline Male & & $5(8.9 \%)$ & $29(51.8 \%)$ & 1.416 & 0.234 \\
\hline Female & & $1(1.8 \%)$ & $21(37.5 \%)$ & & \\
\hline Age (y) & 56 & & & & \\
\hline$\leq 60$ & & $3(5.4 \%)$ & $25(4.6 \%)$ & 0 & 1 \\
\hline$>60$ & & $3(5.4 \%)$ & $25(44.6 \%)$ & & \\
\hline Degree of & 56 & & & & \\
\hline Differentiation & & & & 0.585 & 0.444 \\
\hline Poor & & $2(3.6 \%)$ & $25(44.6 \%)$ & 0.303 & 0.444 \\
\hline Moderate and Well & & $4(7.1 \%)$ & $25(44.6 \%)$ & & \\
\hline Tumor size & 56 & & & & \\
\hline$>3 \mathrm{~cm}$ & & $4(7.1 \%)$ & $27(48.2 \%)$ & 0.342 & 0.559 \\
\hline$\leq 3 \mathrm{~cm}$ & & $2(3.6 \%)$ & $23(41.1 \%)$ & & \\
\hline lymphatic invasion & 56 & & & & \\
\hline Yes & & $4(7.1 \%)$ & $25(44.6 \%)$ & 0.585 & 0.444 \\
\hline No & & $2(3.6 \%)$ & $25(44.6 \%)$ & & \\
\hline TNM stage & 56 & & & & \\
\hline I+II stage & & $4(7.1 \%)$ & $45(80.4 \%)$ & 2.619 & 0.106 \\
\hline III+IV stage & & $2(3.6 \%)$ & $5(8.9 \%)$ & & \\
\hline Smoke & 56 & & & & \\
\hline Yes & & $2(3.6 \%)$ & $4(7.1 \%)$ & 0.244 & 0.621 \\
\hline No & & $22(39.3 \%)$ & $28(50.0 \%)$ & & \\
\hline
\end{tabular}

from LAC and LSCC patients. Samples were collected from patients with parapneumonic, tuberculous, LAC or LSCC pleural effusion, and Shh level was detected by ELISA assay. We analyzed Shh level according to diagnosed disease type and the results showed that Shh level in LSCC pleural effusion was higher than that of parapneumonic and LAC pleural effusion (Figure 4A). Further, parapneumonic and tuberculous pleural effusion was classified as benign pleural effusion, LAC and LSCC pleural effusion was defined as malignant pleural effusion, according to the presence of tumor cells in pleural effusion or in biopsy specimens. There has been no difference in Shh levels between benign and malignant pleural effusion (Figure 4B). Therefore, Shh protein level is elevated in pleural effusion from LSCC patients.

\section{Discussion}

Lung cancer remains the leading cause of cancer-related mortality around the world [22]. According to histological characteristics, those diagnosed lung cancer were classified as NSCLC and SCLC. NSCLC were mostly composed of LAC and LSCC [23]. According to present treatment options, a folate antimetabolite Pemetrexed is only effective for LAC treatment [24, 25], an angiogenesis inhibitor Bevacizumab should be avoided in treating LSCC [26]. As mutations of epidermal growth factor receptor kinase (EGFR) and gene rearrangement of anaplastic lymphoma kinase $(A L K)$ only
Table 2. Association of Shh expression levels with clinicopathologic characteristics in LSCC.

\begin{tabular}{|c|c|c|c|c|c|}
\hline \multirow{2}{*}{$\begin{array}{l}\text { Clinicopathologic } \\
\text { Characteristics }\end{array}$} & \multirow{2}{*}{$\mathbf{n}$} & \multicolumn{2}{|c|}{ Shh expression } & \multirow{2}{*}{$\chi^{2}$ value } & \multirow{2}{*}{ p-value } \\
\hline & & Low (\%) & High (\%) & & \\
\hline Gender & 111 & & & & \\
\hline Male & & $27(24.3 \%)$ & $75(67.6 \%)$ & 1.025 & 0.311 \\
\hline Female & & $1(0.9 \%)$ & $8(7.2 \%)$ & & \\
\hline Age (y) & 111 & & & & \\
\hline$\leq 60$ & & $14(12.6 \%)$ & $33(29.7 \%)$ & 0.891 & 0.345 \\
\hline$>60$ & & $14(12.6 \%)$ & $50(45.0 \%)$ & & \\
\hline Degree of & 111 & & & & \\
\hline Differentiation & & & & 2.882 & 0.045 \\
\hline Poor & & $8(7.2 \%)$ & $3935.1(\%)$ & & \\
\hline Moderate and Well & & $20(18.0 \%)$ & $44(39.6 \%)$ & & \\
\hline Tumor size & 111 & & & & \\
\hline$>3 \mathrm{~cm}$ & & $25(22.5 \%)$ & $54(48.6 \%)$ & 5.935 & 0.015 \\
\hline$\leq 3 \mathrm{~cm}$ & & $3(2.7 \%)$ & $29(26.1 \%)$ & & \\
\hline lymphatic invasion & 111 & & & & \\
\hline Yes & & $9(8.1 \%)$ & $28(25.2 \%)$ & 0.024 & 0.877 \\
\hline No & & $19(17.1 \%)$ & $55(49.5 \%)$ & & \\
\hline TNM stage & 111 & & & & \\
\hline I+II stage & & $25(22.5 \%)$ & $74(66.7 \%)$ & 0 & 0.985 \\
\hline III+IV stage & & $3(2.7 \%)$ & $9(8.1 \%)$ & & \\
\hline Smoke & 111 & & & & \\
\hline Yes & & $19(17.1 \%)$ & $63(56.8 \%)$ & 0.702 & 0.402 \\
\hline No & & $9(8.1 \%)$ & $20(18.0 \%)$ & & \\
\hline
\end{tabular}

occur in patients with LAC, EGFR inhibitors and Crizotinib result in a marked advance in LAC treatment and are mostly ineffective against LSCC $[27,28]$. However, treatment of LSCC is still with conventional platinum-based chemotherapy. Although, it was suggested that Shh was associated with the progression of NSCLC, the expression of Shh in specimens from NSCLC patients needs to be analyzed according to sub-type tumor. We conducted IHC assay to evaluate Shh expression in LAC and LSCC tissues and the paired adjacent normal tissues. The results demonstrated that Shh expression level was higher in both LAC and LSCC tumor tissues than in adjacent tissues (Figures 1 and 2). However, Shh expression is negatively correlated with differentiation of tumor only in LSCC and LSCC patients with higher level of Shh expression have a poor prognosis (Figure 3). The different mechanisms of Shh in development and progression of LAC and LSCC need to be explored.

Patients with lung cancer frequently have pleural effusion at the time of initial diagnosis or in the course of disease progression [29]. Shh protein levels showed no difference between malignant and benign pleural effusion, while it was increased in pleural effusion from LSCC patients compared with that of parapneumonic and LAC pleural effusion (Figure 4). Pleural effusion of LSCC contains higher Shh level than in parapneumonic pleural effusion. However, we found that Shh cannot distinguish tuberculosis and LSCC. It has been reported that Minocycline has direct potent 

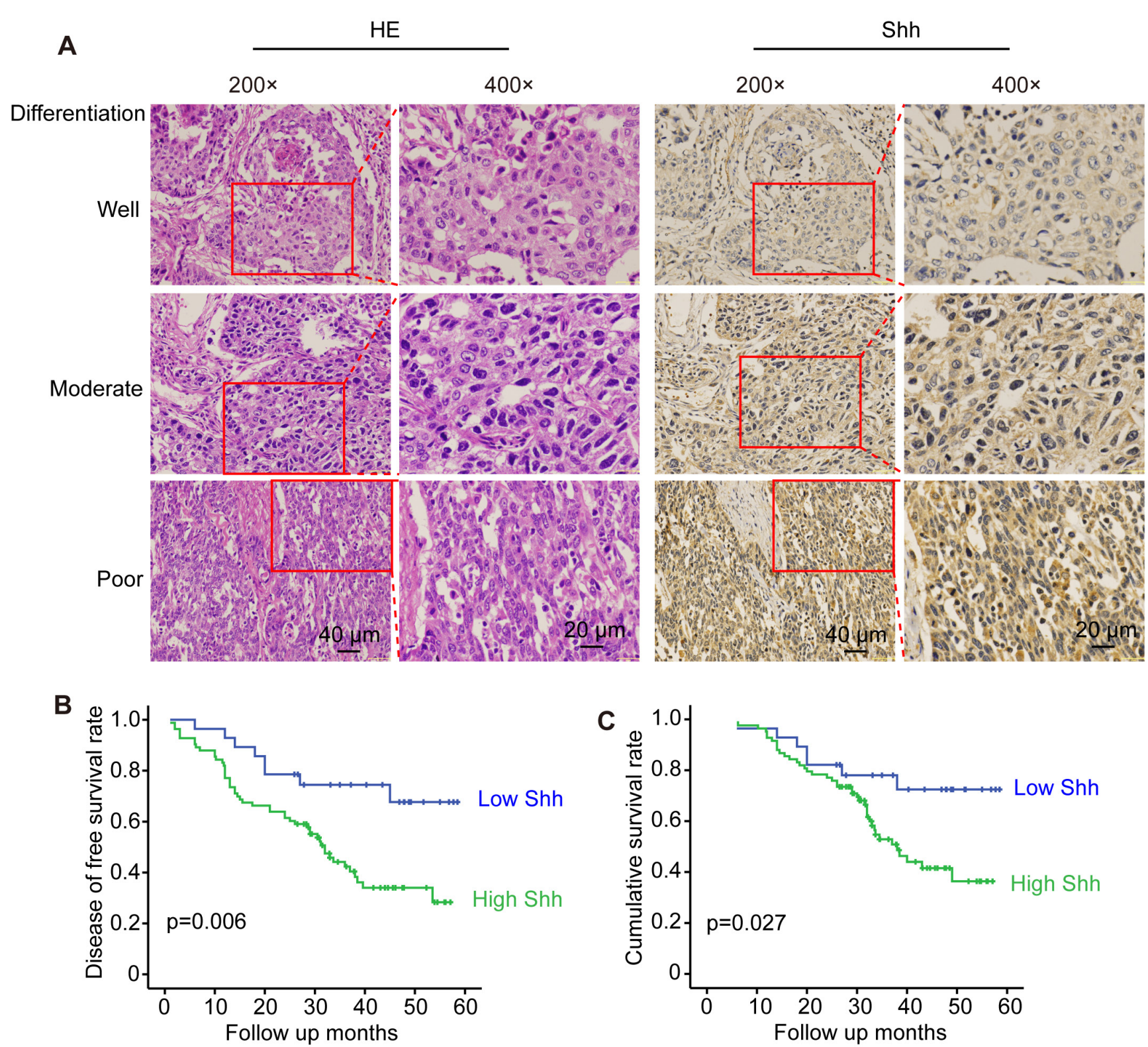

Figure 3. Shh level correlates with poor prognosis in LSCC. A) Shh level increases along with grade progression in LSCC, representative images are shown. B-C) High level of Shh resulted in poor survival in patients with LSCC. Univariate analysis was employed to analysis disease-free survival and overall survival of LSCC patients.

effect against drug-resistant tuberculosis through inhibiting Hh signaling [30], which indicates that Hh signaling may be associated with tuberculosis. But the precise molecular mechanism of $\mathrm{Hh}$ signaling in the pathogenesis of tuberculosis needs to be uncovered. Whether Shh level is also elevated in serum from LSCC patients has yet to be determined as the serum from LAC or LSCC patients is unavailable for us. Shh level in pleural effusion may be used to diagnose LSCC, and to distinguish between LAC and LSCC.

Our findings suggest that Shh does not manifest the same way in LAC and LSCC. Our results indicate that expression of
Shh is increased in tumor tissues from both LAC and LSCC patients compared with the paired adjacent tissues. While Shh level is negatively correlated with tumor differentiation only in LSCC, LSCC patients containing higher expression of Shh have a poorer prognosis. Furthermore, Shh level is also elevated in pleural effusion from LSCC patients compared with that of parapneumonic and LAC pleural effusion. In a word, Shh expression in tumor tissues or pleural effusion may represent a useful diagnostic and prognostic marker of LSCC patients and Shh may play an important role in the pathogenesis of LSCC. 

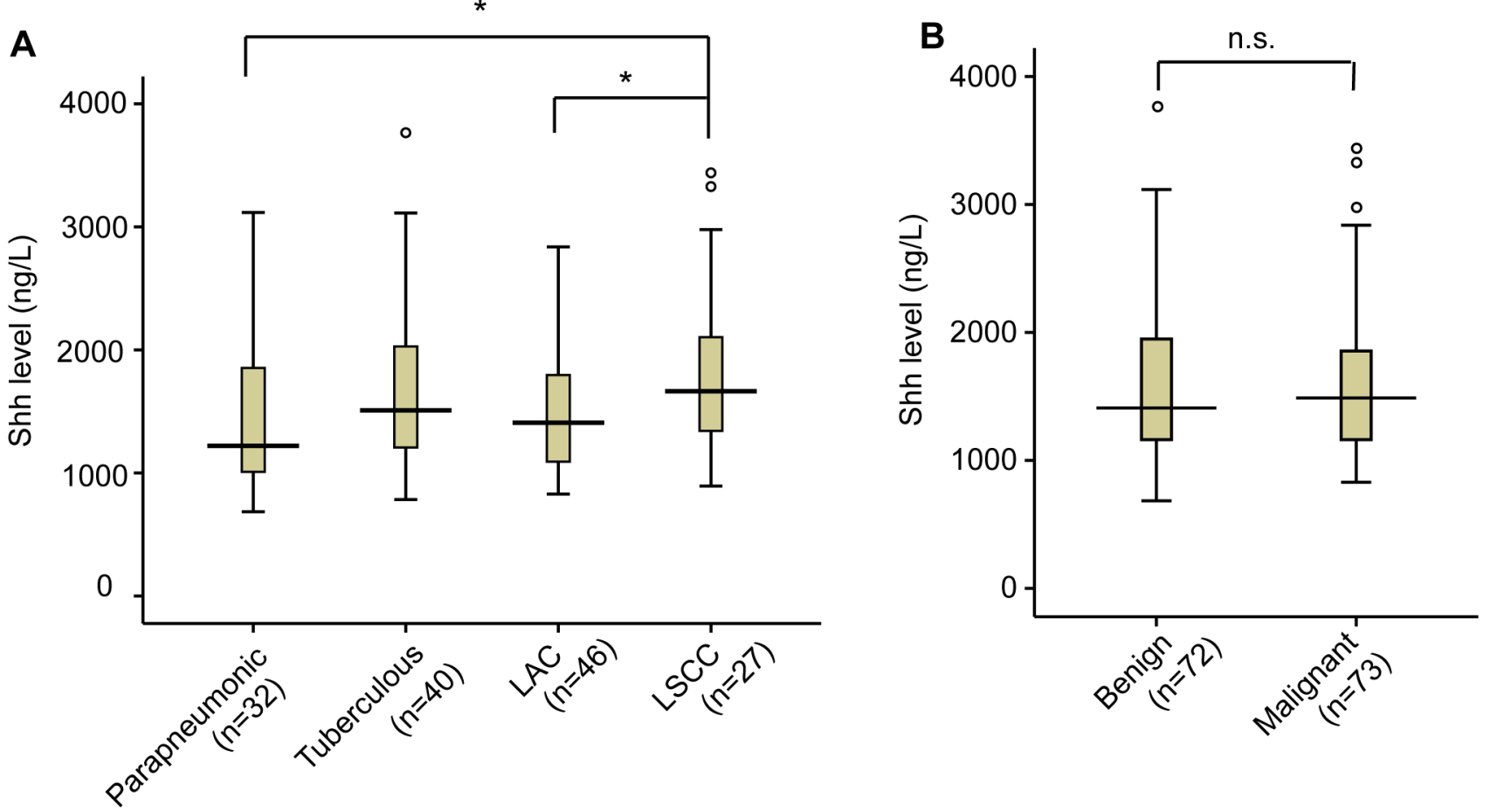

Figure 4. Pleural effusion of Shh level is elevated in LSCC patients. A) Levels of Shh in parapneumonic, tuberculous, LAC or LSCC pleural effusion. ${ }^{*} \mathbf{p}<0.05$. B) Levels of Shh in benign and malignant pleural effusion. n.s. - no significance.

Acknowledgements: This work was supported in part by grants from the National Natural Science Foundation of China (81660461 to Limin Chen, 81460376 to Linlin Xu).

\section{References}

[1] SIEGEL RL, MILLER KD, JEMAL A. Cancer statistics, 2018. CA Cancer J Clin 2018; 68: 7-30. https://doi.org/10.3322/ caac. 21442

[2] CAMPBELL JD, ALEXANDROV A, KIM J, WALA J, BERGER AH et al. Distinct patterns of somatic genome alterations in lung adenocarcinomas and squamous cell carcinomas. Nat Genet 2016; 48: 607-616. https://doi. org/10.1038/ng.3564

[3] MA Y, FAN M, DAI L, KANG X, LIU Y et al. Expression of p63 and ck5/6 in early-stage lung squamous cell carcinoma is not only an early diagnostic indicator but also correlates with a good prognosis. Thorac Cancer 2015; 6: 288-295. https:// doi.org/10.1111/1759-7714.12181

[4] BRISCOE J, THEROND PP. The mechanisms of hedgehog signalling and its roles in development and disease. Nat Rev Mol Cell Biol 2013; 14: 416-429. https://doi.org/10.1038/ nrm3598

[5] INGHAM PW, MCMAHON AP. Hedgehog signaling in animal development: Paradigms and principles. Genes Dev 2001; 15: 3059-3087. https://doi.org/10.1101/ $\operatorname{gad} .938601$
[6] PEPINSKY RB, RAYHORN P, DAY ES, DERGAY A, WILLIAMS KP et al. Mapping sonic hedgehog-receptor interactions by steric interference. J Biol Chem 2000; 275: 1099511001. https://doi.org/10.1074/jbc.275.15.10995

[7] GONG X, QIAN H, CAO P, ZHAO X, ZHOU Q et al. Structural basis for the recognition of sonic hedgehog by human patched1. Science 2018; 361. https://doi.org/10.1126/science.aas 8935

[8] HUMKE EW, DORN KV, MILENKOVIC L, SCOTT MP, ROHATGI R. The output of hedgehog signaling is controlled by the dynamic association between suppressor of fused and the gli proteins. Genes Dev 2010; 24: 670-682. https://doi. org/10.1101/gad.1902910

[9] HUI CC, ANGERS S. Gli proteins in development and disease. Annu Rev Cell Dev Biol 2011; 27: 513-537. https://doi. org/10.1146/annurev-cellbio-092910-154048

[10] SCALES SJ, DE SAUVAGE FJ. Mechanisms of hedgehog pathway activation in cancer and implications for therapy. Trends Pharmacol Sci 2009; 30: 303-312. https://doi. org/10.1016/j.tips.2009.03.007

[11] BELLUSCI S, FURUTA Y, RUSH MG, HENDERSON R, WINNIER G et al. Involvement of sonic hedgehog (shh) in mouse embryonic lung growth and morphogenesis. Development 1997; 124: 53-63.

[12] ORO AE, HIGGINS KM, HU Z, BONIFAS JM, EPSTEIN $\mathrm{EH}$ et al. Basal cell carcinomas in mice overexpressing sonic hedgehog. Science 1997; 276: 817-821. https://doi. org/10.1126/science.276.5313.817 
[13] TEGLUND S, TOFTGARD R. Hedgehog beyond medulloblastoma and basal cell carcinoma. Biochim Biophys Acta 2010; 1805: 181-208. https://doi.org/10.1016/j. bbcan.2010.01.003

[14] SHAO J, XU L, CHEN L, LU Q, XIE X et al. Arl13b promotes gastric tumorigenesis by regulating smo trafficking and activation of the hedgehog signaling pathway. Cancer Res 2017; 77: 4000-4013. https://doi.org/10.1158/0008-5472.CAN-162461

[15] SZCZEPNY A, ROGERS S, JAYASEKARA WSN, PARK K, MCCLOY RA et al. The role of canonical and non-canonical hedgehog signaling in tumor progression in a mouse model of small cell lung cancer. Oncogene 2017; 36: 5544-5550. https://doi.org/10.1038/onc.2017.173

[16] SKODA AM, SIMOVIC D, KARIN V, KARDUM V, VRANIC $S$ et al. The role of the hedgehog signaling pathway in cancer: A comprehensive review. Bosn J Basic Med Sci 2018; 18: 8-20. https://doi.org/10.17305/bjbms.2018.2756

[17] GIROUX LEPRIEUR E, ANTOINE M, VIEIRA T, ROZENSZTAJN N, RUPPERT AM et al. [Role of the sonic hedgehog pathway in thoracic cancers]. Rev Mal Respir 2015; 32: 800-808. https://doi.org/10.1016/j.rmr.2014.11.069

[18] JIANG WG, YE L, RUGE F, SUN P-H, SANDERS AJ et al. Expression of Sonic Hedgehog (SHH) in human lung cancer and the impact of YangZheng XiaoJi on SHH-mediated biological function of lung cancer cells and tumor growth. Anticancer Res 2015; 35: 1321-1331.

[19] WATKINS DN, BERMAN DM, BURKHOLDER SG, WANG B, BEACHY PA et al. Hedgehog signalling within airway epithelial progenitors and in small-cell lung cancer. Nature 2003; 422: 313-317. https://doi.org/10.1038/nature01493

[20] SAVANI M, GUO Y, CARBONE DP, CSIKI I. Sonic hedgehog pathway expression in non-small cell lung cancer. Ther Adv Med Oncol 2012; 4: 225-233. https://doi. org/10.1177/1758834012450362

[21] XU C, YU L, ZHAN P, ZHANG Y. Elevated pleural effusion il-17 is a diagnostic marker and outcome predictor in lung cancer patients. Eur J Med Res 2014; 19: 23. https://doi. org/10.1186/2047-783X-19-23

[22] SIEGEL RL, MILLER KD, JEMAL A. Cancer statistics, 2017. CA Cancer J Clin 2017; 67: 7-30. https://doi.org/10.3322/ caac. 21387
[23] JUSTILIEN V, WALSH MP, ALI SA, THOMPSON EA, MURRAY NR et al. The PRKCI and SOX2 oncogenes are coamplified and cooperate to activate Hedgehog signaling in lung squamous cell carcinoma. Cancer Cell 2014; 25: 139151. https://doi.org/10.1016/j.ccr.2014.01.008

[24] HANNA N, SHEPHERD FA, FOSSELLA FV, PEREIRA JR, MARINIS FD et al. Randomized phase iii trial of pemetrexed versus docetaxel in patients with non-small-cell lung cancer previously treated with chemotherapy. Journal of Clinical Oncology 2004; 22: 1589-1597. https://doi.org/10.1200/ JCO.2004.08.163

[25] CIULEANU T, BRODOWICZ T, ZIELINSKI C, KIM JH, KRZAKOWSKI $\mathrm{M}$ et al. Maintenance pemetrexed plus best supportive care versus placebo plus best supportive care for non-small-cell lung cancer: A randomised, double-blind, phase 3 study. Lancet 2009; 374: 1432-1440. https://doi. org/10.1016/S0140-6736(09)61497-5

[26] SANDLER A, GRAY R, PERRY MC, BRAHMER J, SCHILLER JH et al. Paclitaxel-carboplatin alone or with bevacizumab for non-small-cell lung cancer. N Engl J Med 2006; 355: 2542-2550. https://doi.org/10.1056/NEJMoa061884

[27] SODA M, CHOI YL, ENOMOTO M, TAKADA S, YAMASHITA $Y$ et al. Identification of the transforming EML4-ALK fusion gene in non-small-cell lung cancer. Nature 2007; 448: 561. https://doi.org/10.1038/nature05945

[28] LYNCH TJ, BELL DW, SORDELLA R, GURUBHAGAVATULA S, OKIMOTO RA et al. Activating mutations in the epidermal growth factor receptor underlying responsiveness of non-small-cell lung cancer to gefitinib. N Engl J Med 2004; 350: 2129-2139. https://doi.org/10.1056/NEJMoa040938

[29] CHENG D, LIANG B, LI YH. Application of MMP-7 and MMP-10 in assisting the diagnosis of malignant pleural effusion. Asian Pac J Cancer Prev 2012; 13: 505-509.

[30] DESHPANDE D, PASIPANODYA JG, SRIVASTAVA S, MARTIN KR, ATHALE $S$ et al. Minocycline immunomodulates via sonic hedgehog signaling and apoptosis and has direct potency against drug-resistant tuberculosis. J Infect Dis 2019; 219: 975-985. https://doi.org/10.1093/infdis/ jiy587 